\section{Endoscopic Removal of a Perforating Toothpick}

Foreign bodies in the colon are encountered with increasing frequency, but, to date, only sporadic reports concerning their management have appeared in the literature $[1,2]$. While most ingested foreign bodies usually pass through the gastrointestinal tract uneventfully, sharp foreign bodies such as toothpicks infrequently cause intestinal perforation and may even result in death [3].

We describe the case of a woman with abdominal pain caused by a toothpick perforating the sigmoid colon. The foreign body was diagnosed and removed during colonoscopy after abdominal exploration and appendectomy had not disclosed any abnormalities.

A 52-year-old woman with a 2-week history of upper and lower abdominal pain was admitted with acute pain in the right lower quadrant. A presumptive diagnosis of appendicitis was made, and the patient underwent emergency laparotomy. The appendix was normal, and an abdominal exploration disclosed no abnormalities. Postoperatively, the symptoms remained with progressive abdominal distension and pain, and were followed by the appearance of rectal bleeding. A colonoscopy was performed 10 days after laparotomy and revealed a fixed sigmoid loop with a toothpick of $9 \mathrm{~cm}$ length that had perforated the sigmoid colon (Figure 1). The toothpick was removed using foreign-body extraction forceps (Figure 2). Although the abdominal radiograph showed free air as a sign of perforation, the patient's recovery was uncomplicated, with antibiotic therapy. The perforation edges were closed primarily. The circumstances of the foreign body ingestion remained unclear.

This case emphasizes the uncommon but potentially lethal hazards associated with the ingestion of toothpicks. Such sharp objects may cause localized acute inflammatory mass or acute diffuse peritonitis and present with signs of an acute abdomen or an appendicitis. If this unusual but important cause of abdominal pain is taken into account and diagnosed in time, endoscopic management is possible.

\section{H. H. Mohr, A. Dierkes-Globisch}

Dept. of Internal Medicine, Central Hospital of German Armed Forces Koblenz, Medical Division, Johannes-Gutenberg University, Mainz, Germany

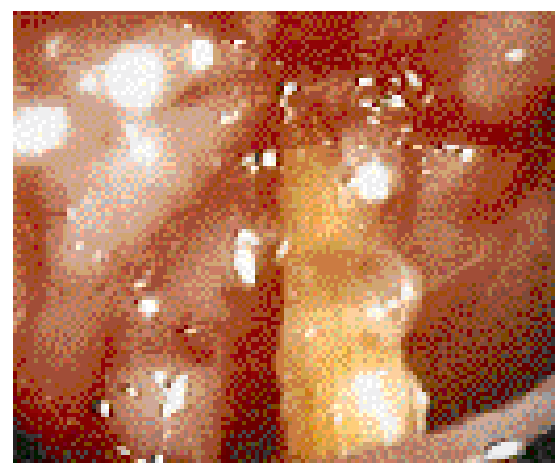

Figure 1 The endoscopic appearance of the toothpick in the sigmoid colon

\section{References}

${ }^{1}$ Ooi S-W, Ho Y-H, EU KW, et al. Management of anorectal foreign bodies. A cause of obscure anal pain. Aust N Z J Surg 1998; 68: 852-855

2 Selivanov V, Sheldon GF, Cello JP, Crass RA. Management of foreign body ingestion. Ann Surg 1984; 99: 187-191

${ }^{3}$ Cockerill FR, Wilson WR, van Scoy RE. Traveling toothpicks. Mayo Clin Proc 1983; 58: 613-616

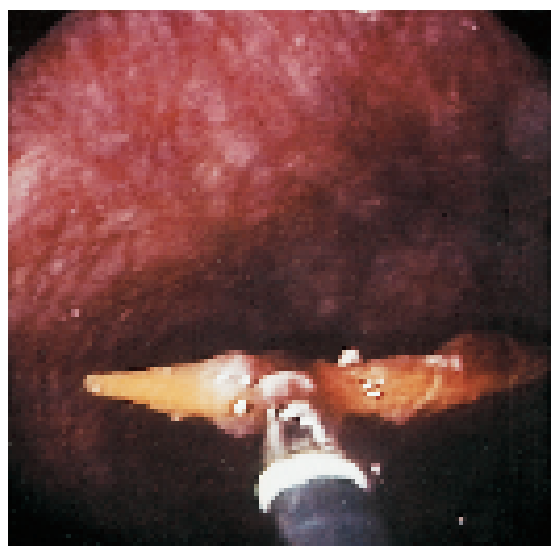

Figure 2 Removal of the toothpick was achieved using foreign-body extraction forceps

Corresponding Author

H.-H.Mohr, M.D.

Abteilung 1, Innere Medizin

Bundeswehrzentralkrankenhaus Koblenz

Rübenacher Strasse 170

56064 Koblenz

Germany

Fax: $\quad+49-2-612812103$

E-mail: Dr.Hans.Mohr@t-online.de 